\title{
A INTERCALAÇÃO ADMINISTRATIVA NA REGULAÇÃO DA SAÚDE SUPLEMENTAR: IMPLICAÇÕES CONSTITUCIONAIS DO AFASTAMENTO RELATIVO DO REGIME FALENCIAL
}

\author{
ADMINISTRATIVE INTERLEAVING IN SUPPLEMENTAL HEALTH \\ REGULATION: CONSTITUTIONAL IMPLICATIONS OF THE RELATIVE \\ DISREGARDING OF BANKRUPT REGIME
}

\author{
Cássio Luís Casagrande \\ Universidade Federal Fluminense - UFF - (Niterói, RJ, Brasil)
}

Dalton Robert Tibúrcio

Universidade Federal Fluminense - UFF - (Niterói, RJ, Brasil)

Recebimento: 4 abr. 2018

Aceitação: 10 jul. 2018

\begin{abstract}
Como citar este artigo / How to cite this article (informe a data atual de acesso / inform the current date of access):
CASAGRANDE, Cássio Luís; TIBÚRCIO, Dalton Robert. A intercalação administrativa na regulação da saúde suplementar: implicações constitucionais do afastamento relativo do regime falencial. Revista da Faculdade de Direito UFPR, Curitiba, PR, Brasil, v. 63, n. 3, p. 9-35, set./dez. 2018. ISSN 2236-7284. Disponível em: <https://revistas.ufpr.br/direito/article/view/58717>. Acesso $\quad$ em: 22 dez. $2018 . \quad$ DOI:
\end{abstract} http://dx.doi.org/10.5380/rfdufpr.v63i3.58717.

\section{RESUMO}

O presente texto investiga a intercalação administrativa decorrente do afastamento relativo do regime falencial em favor da competência da Agência Nacional de Saúde Suplementar para proceder à liquidação extrajudicial de operadoras de planos de saúde. O artigo compreende esse fenômeno como uma manifestação dos poderes quase-judiciais da função regulatória, refletindo sobre suas implicações constitucionais. O artigo analisa a prevalência circunstancial e transitória da via administrativa sobre a judicial, diante da garantia da inafastabilidade da jurisdição e do princípio da separação de poderes. Por fim, o texto verifica as consequências do afastamento da via judicial ordinária no âmbito infraconstitucional para os credores e para os sócios das operadoras de planos de saúde, bem como a possibilidade de conversão da liquidação extrajudicial em falência ou insolvência civil. A partir do levantamento do histórico da legislação, bem como da pesquisa bibliográfica e jurisprudencial, o estudo situa a liquidação extrajudicial de operadoras de planos de saúde como um instituto relevante para a regulação da saúde suplementar no Brasil.

\section{PALAVRAS-CHAVE}

Regulação. Saúde suplementar. Separação de poderes. Liquidação. Planos de saúde.

\section{ABSTRACT}

This paper seeks to identify the administrative interleaving as a result of the relative disregard of bankruptcy system in favor of the administrative power of Brazilian Regulatory Agency for the healthcare plans market to carry out extrajudicial liquidation of healthcare plans operators. The article considers that phenomenon as a manifestation of the almost jurisdictional powers of regulatory function, reflecting on the constitutional implications. The article analyzes the circumstantial and 
transitory prevalence of the administrative sphere over the judicial one, before the guarantee of the non-obviation of jurisdiction and separation of powers. Finally, the text verifies the consequences of the removal of the ordinary judicial sphere in the infra-constitutional level to the creditors and the partners of healthcare plans operators, as well as the possibility of converting the extrajudicial liquidation in bankruptcy or civil insolvency suit. From the review of the legislation history, as well as the bibliographical and jurisprudential research, the study establishes the extrajudicial liquidation of health plan operators as a relevant institute for the regulation of supplementary health in Brazil.

\section{KEYWORDS}

Regulation. Supplementary health. Separation of powers. Liquidation. Health care plans.

\section{INTRODUÇÃO}

A comercialização de planos privados de assistência à saúde, embora seja uma atividade econômica que se expandiu impulsionada pela política estatal implementada a partir de 1964 de privilegiar o setor privado de serviços de saúde, como destaca Escorel (2012, p. 327-328), somente contou com uma disciplina regulatória específica a partir do final dos anos de 1990. Quase 10 anos após a promulgação da Constituição, foi editada a Lei nº 9.656, de 3 de junho de 1998, concretizando o comando constitucional que estabelece ser a assistência privada à saúde uma atividade livre à iniciativa privada, mas de relevância pública e sujeita à regulamentação, fiscalização e controle do Poder Público (CRFB/88, art. 197 e 199), como ressalta Sarrubbo (1999, p. 17).

Figueiredo (2012, p. 127) destaca que, logo após a edição da Lei nº 9.656/98, a competência regulatória sobre o mercado de saúde suplementar foi partilhada entre o Ministério da Fazenda, por meio da Superintendência de Seguros Privados, e o Ministério da Saúde, por meio da Secretaria de Assistência à Saúde, ficando o primeiro responsável pelos aspectos econômico-financeiros e o último pelos aspectos assistenciais. No entanto, seguindo o modelo de agências reguladoras introduzido no Brasil a partir de 1996, foi criada, no ano 2000, a Agência Nacional de Saúde Suplementar (ANS), com a finalidade institucional de "promover a defesa do interesse público na assistência suplementar à saúde, regulando as operadoras setoriais, inclusive quanto às suas relações com prestadores e consumidores, contribuindo para o desenvolvimento das ações de saúde no País” (art. $3^{\circ}$ da Lei no 9.961/2000).

Apesar do ineditismo da regulação sistemática de um setor da economia bastante heterogêneo, em função da diversidade dos atores que nele atuam - seguradoras, cooperativas, entidades de autogestão, filantrópicas, empresas de medicina de grupo -, já havia, no ordenamento brasileiro, uma vasta experiência na disciplina da atividade de seguros que, ao menos do ponto de vista econômico, como indica Alves (2015, p. 42-43), abrange o cerne da operação de planos de 
saúde. Portanto, é natural que a legislação que passou a cuidar da regulação da saúde suplementar tenha buscado apoio em institutos da regulação de seguros.

Assim, por exemplo, a autorização de funcionamento, prevista no Decreto-Lei nº 73/66 (art. 74 e seguintes), que disciplina a atividade de seguros, foi o instrumento jurídico previsto pela legislação da saúde suplementar (Lei n 9.656/98, art. 8º para o controle do ingresso dos agentes econômicos no segmento regulado e também para o contínuo acompanhamento do exercício da atividade, de modo a ordená-la de acordo com os interesses públicos a serem atendidos. Além disso, a Lei $n^{\circ}$ 9.656/98, em seu art. 241 , dotou a ANS de mecanismos específicos de intervenção na atividade das operadoras de planos de assistência à saúde: a alienação da carteira, o regime de direção fiscal ou técnica e a liquidação extrajudicial. Os regimes especiais previstos no art. 24 da Lei $n^{\circ}$ 9.656/98 guardam estreita inspiração com o modelo previsto no Decreto-Lei 73/66 para a liquidação das sociedades seguradoras e especialmente com os institutos previstos na Lei ${ }^{\circ} 6.024 / 74$, que dispõe sobre os mecanismos de intervenção nas instituições financeiras.

Os regimes especiais são a forma mais intensa de intervenção estatal sobre a atividade privada de operação de planos de saúde. São medidas administrativas que restringem, em graus variados, a livre iniciativa e a liberdade econômica das empresas. Os agentes econômicos privados se sujeitam a um estado jurídico excepcional, que vai desde a imposição de obrigações temporárias menos invasivas até a dissolução administrativa forçada. Assim, por determinação da ANS, por exemplo, as operadoras de planos de saúde podem se sujeitar ao cumprimento das diretivas do diretor fiscal ou diretor técnico, podem ser obrigadas a alienar a sua carteira de beneficiários, ou até mesmo podem ser liquidadas extrajudicialmente.

Um aspecto de grande relevância do estado jurídico excepcional dos regimes especiais é o afastamento relativo do regime falencial no momento da crise econômico-financeira das operadoras de planos de saúde, que decorre da adoção, pela Lei n ${ }^{\circ}$ 9.656/98, da liquidação extrajudicial para o encerramento compulsório das atividades das empresas atuantes no setor regulado.

Dessa forma, as operadoras de planos de saúde não estão sujeitas ao regime ordinário de insolvência empresarial. Para garantir a preservação dos interesses públicos e privados justificadores da regulação desse setor da economia, a Lei instituiu um sistema análogo ao previsto para outras

\footnotetext{
1 “Art. 24. Sempre que detectadas nas operadoras sujeitas à disciplina desta Lei insuficiência das garantias do equilíbrio financeiro, anormalidades econômico-financeiras ou administrativas graves que coloquem em risco a continuidade ou a qualidade do atendimento à saúde, a ANS poderá determinar a alienação da carteira, o regime de direção fiscal ou técnica, por prazo não superior a trezentos e sessenta e cinco dias, ou a liquidação extrajudicial, conforme a gravidade do caso.”
} 
empresas (como as instituições financeiras e as seguradoras), no qual em um primeiro momento a solução judicial da falência é afastada em favor de uma solução substitutiva, pela via administrativa.

A prevalência, ainda que transitória e circunstancial, da via administrativa sobre a judicial, traz à evidência a importante questão constitucional acerca da compatibilidade desse regime com a garantia da inafastabilidade da jurisdição e com o princípio da separação de poderes. Ressalta Asimow (2017, p. 131) que sistemas administrativos que conferem à Administração a competência para solucionar conflitos entre particulares costumam despertar a desconfiança judicial, em razão da ameaça que representam aos poderes dos magistrados. Tanto é assim que Rubens Requião aponta que o problema mais relevante no estudo das liquidações extrajudiciais é responder à seguinte pergunta: “Os processos de intervenção e de liquidação extrajudicial excluem o processo de falência da empresa financeira submetida a uma dessas medidas?” (REQUIÃO, 1995, p. 210-211).

No presente artigo, a partir de pesquisa bibliográfica e jurisprudencial, demonstraremos como historicamente o instituto da liquidação extrajudicial foi construído em conexão com o afastamento do regime falencial. Enfrentaremos a questão constitucional que esse estado jurídico excepcional suscita, atinente à inafastabilidade da jurisdição e à separação de poderes. A hipótese sustentada é a de que não há inconstitucionalidade no tratamento da matéria, uma vez que se trata meramente da intercalação da esfera administrativa, previamente à judicial, sem importar em afronta a direitos subjetivos, tampouco em usurpação da função jurisdicional. Analisaremos, ainda, as consequências no âmbito infraconstitucional do afastamento da via judicial ordinária, em especial para os credores e para os sócios das operadoras de planos de saúde e desvendaremos a natureza da liquidação extrajudicial. Por fim, analisaremos como a liquidação extrajudicial se converte em falência ou insolvência civil.

\section{O PERCURSO HISTÓRICO DO AFASTAMENTO DO REGIME FALENCIAL POR FORÇA DA ADOÇÃO DO INSTITUTO DA LIQUIDAÇÃO EXTRAJUDICIAL}

O intérprete, ao tentar identificar o arcabouço legal incidente sobre as relações jurídicas decorrentes da crise econômico-financeira das operadoras de planos privados de assistência à saúde, depara-se com uma aparente contradição ou mesmo uma indefinição quanto aos termos usados pela Lei.

A confusão interpretativa começa quando a Lei no 11.101/2005 estipula, em seu art. $2^{\circ}$, II, que seus dispositivos não se aplicam às sociedades operadoras de planos de assistência à saúde, dentre outras empresas. Também a Lei $n^{\circ}$ 9.656/98, estipula, em seu art. 23, caput, que as operadoras de 
planos privados de assistência à saúde não podem requerer concordata e não estão sujeitas a falência ou insolvência civil, mas tão somente ao regime de liquidação extrajudicial. No entanto, a própria Lei 11.101/2005, em seu art. 197, estipula a sua aplicação subsidiária, no que couber, aos regimes de liquidação extrajudicial previstos no Decreto-Lei $n^{0} 73 / 66$, na Lei $n^{0} 6.024 / 74$, no Decreto-Lei ${ }^{0}$ 2.321/87 e na Lei ${ }^{0}$ 9.514/97, até que sejam aprovadas as respectivas leis específicas.

A remissão normativa já se encontrava no art. 34 da Lei $n^{\circ}$ 6.024/74, que manda aplicar a Lei de Falência, no que couber, à liquidação extrajudicial das instituições financeiras. Por sua vez, o art. 24-D, da Lei n ${ }^{0}$ 9.656/98, ao dispor sobre as normas aplicáveis à liquidação extrajudicial das operadoras de planos de saúde, aponta um conjunto de leis a serem utilizadas: Lei no 6.024/74, Decreto-Lei no 7.661/45, Decreto-Lei no 41/66 e Decreto-Lei no 73/66. A superveniência da Lei no 11.101/2005 operou a alteração semântica do art. 24-D da Lei no 9.656/98, que previa a aplicação da antiga Lei de Falências (Decreto-Lei n ${ }^{\circ}$ 7.661/45) à liquidação extrajudicial das operadoras de planos de saúde, de maneira que a remissão deve passar a ser interpretada como feita à Lei no 11.101/2005. Assim, a própria Lei nº 11.101/2005 resulta aplicável, ao menos de forma subsidiária, à liquidação de operadoras de planos de saúde, seja pela interpretação evolutiva à referência ao Decreto-Lei $\mathrm{n}^{0}$ 7.661/45 (antiga Lei de Falências) ou mesmo por força do disposto no art. 197 da Lei nº 11.101/2005, combinado com a norma de reenvio do art. 24-D da Lei nº 9.656/98 e com o art. 34 da Lei n 6.024/74.

Não bastasse isso, a Lei $n^{0} 9.656 / 98$, em seu art. 23, $\S 1^{\circ}$, estipula que as operadoras de planos de saúde sujeitar-se-ão ao regime de falência ou insolvência civil quando, no curso da liquidação extrajudicial, se verificarem quaisquer das hipóteses arroladas nos incisos do referido parágrafo. Observemos que o art. 24-D da Lei n ${ }^{\circ}$ 9.656/98 não deve ser lido apenas como uma norma de interpretação e de integração de lacunas da Lei nº 9.656/98, mas também como uma norma atribuidora de competência (esse o sentido do termo "conforme o que dispuser a ANS" contido na parte final do referido artigo) para o exercício do poder normativo pela Agência Nacional de Saúde Suplementar. Por meio do exercício do poder normativo conferido à Agência (art. $4^{\circ}, \mathrm{XL}, \mathrm{XLI}, c$ e $d$ da Lei $n^{\circ}$ 9.961/2000, art. 24-B e art. 24-D da Lei ${ }^{\circ}$ 9.656/98) para dispor sobre os regimes especiais de saúde suplementar, a ANS tem editado normas que tratam do tema, dentre as quais se destaca a Resolução Normativa ANS nº 316/2012, que dispõe sobre os regimes especiais de direção fiscal e de liquidação extrajudicial das operadoras de planos de assistência à saúde. Assim, devemos ter em vista que o conjunto de normas aplicáveis à liquidação extrajudicial das operadoras de planos de saúde não se restringe às disposições contidas na Lei $n^{0}$ 9.656/98, sendo comum a utilização dos demais ordenamentos setoriais referidos no indicado art. 24-D da Lei ${ }^{\circ}$ 9.656/98. 
Dentre os ordenamentos remetidos pelo art. 24-D da Lei ${ }^{\circ}$ 9.656/98 assume especial importância, além do próprio regime falimentar, o regime da liquidação extrajudicial das instituições financeiras, regido pela Lei $\mathrm{n}^{0}$ 6.024/74, em especial por força da maior produção doutrinária existente sobre o tema, que remonta aos trabalhos clássicos de Waldemar Ferreira (1961), Pontes de Miranda (2003) e Rubens Requião (1995). Assim, no curso do presente artigo serão feitas, em muitas ocasiões, referências às normas dos demais ordenamentos setoriais não apenas por uma questão de identidade de ratio legis, mas por conta do sistema de reenvio normativo previsto no art. 24-D da Lei $n^{\circ} 9.656 / 98$.

A opção do legislador por um complexo sistema de reenvio normativo gerou um quadro obscuro, que por vezes tem resultado em equívocos nas soluções dos casos concretos. Assim, por exemplo, algumas decisões judiciais tem indeferido o pedido de falência de operadora de plano de saúde, embora tenha sido formulado por liquidante extrajudicial, devidamente autorizado pela ANS, sob o argumento de que a Lei 11.101/2005, por ter afastado, em seu art. $2^{\circ}$, II, de sua incidência essas sociedades, teria se tornado incompatível com a Lei $n^{\circ}$ 9.656/98². Encontramos, ainda, decisões judiciais que deferem a recuperação judicial de operadora de planos de saúde, invocando os princípios da preservação da empresa e da função social ${ }^{3}$.

Essas decisões, no entanto, não alcançam a compreensão abrangente da questão. De fato, as operadoras de planos de saúde, de ordinário, não se sujeitarão às regras gerais de falência e de recuperação judicial ou extrajudicial (art. 23, da Lei 9.656/98 e art. 2º, II, da Lei 11.101/2005). Para a solução da crise econômico-financeira dessas sociedades, considerando a natureza da atividade que desempenham, a Lei optou por afastar a solução judicial em favor dos regimes especiais que tramitam na esfera administrativa, os quais podem vir a desaguar na via judicial, desde que atendidos os requisitos legais para tanto.

Para a melhor compreensão da questão, observemos como o desenvolvimento histórico do instituto da liquidação extrajudicial sempre caminhou excepcionando o regime falencial.

Ainda na fase do Império existiram diplomas normativos que afastaram empresas específicas, ou tipos de sociedades, do regime falencial (Decreto 3.308, de 17/9/1864; Decreto 3.309, de 20/9/1864; Decreto 3.471, de 3/6/1865; Lei 3.150, de 4/11/1882), mas todos eles estabeleciam regimes especiais que se processavam perante o juiz, tal como a falência, apenas prevendo rito mais

\footnotetext{
${ }^{2}$ Como se verifica, por exemplo, da decisão proferida em 24 de agosto de 2010 pelo $12^{\circ}$ Ofício da Comarca de Santos/SP, nos autos do processo 0029514-15.2010.8.26.0562 (562.01.2010.029514).

${ }^{3}$ Como é o caso da decisão proferida em 18 de dezembro de 2014, pela 13a Vara Cível Especializada Empresarial de Recuperação Judicial e Falência da Comarca de Vitória/ES, nos autos do processo nº 024140382938.
} 
simples e rápido. Alguns autores, como Abrão (1993, p. 307), no entanto, apontam o Decreto nº 3.309 como o precursor da liquidação extrajudicial, uma vez que embora tenha mantido o procedimento na esfera judicial, conferia "poderes liquidatários a um fiscal do Governo, com autonomia para liquidar as dívidas ativas e passivas do falido” (RODRIGUES, 2004, p. 94).

O caráter administrativo do regime de liquidação especial foi introduzido para o encerramento das operações dos bancos e das casas bancárias, logo após a revolução de 1930, primeiro em caráter transitório pelo Decreto 19.479, de 12/12/1930, e depois de forma definitiva pelo Decreto-Lei 9.228, de 3/5/1946 e pelo Decreto-Lei 9.346, de 10/6/1946. A Lei 4.595, de 31/12/1964, o Decreto-Lei 48, de 18/11/1966 e o Decreto-Lei 685, de 17/07/1969 ampliaram e reforçaram o sistema de intervenção e liquidação das instituições financeiras. A Lei 6.024, de 13/3/1974, consolidou essas previsões legais anteriores, ao dispor sobre o regime de intervenção e liquidação de instituições financeiras, ainda em vigor. O regime da liquidação extrajudicial, em substituição à falência, se estendeu ao longo dos anos a outros ramos de atividades, tais como as sociedades seguradoras, pelo Decreto-Lei 73, de 21/11/1966; as sociedades de capitalização, pelo Decreto-Lei 261, de 28/2/1967; as cooperativas, pela Lei 5.764, de 16/12/1971; os consórcios e fundos de mútuo, pela Lei 5.768, de 20/12/1971; e as entidades de previdência complementar, pela Lei Complementar 109 , de 29/5/2001.

Desde o Decreto 19.479/30 se estabeleceu grande controvérsia em relação à não sujeição das instituições financeiras à falência. A jurisprudência entendia que a submissão das sociedades ao regime de liquidação fora de juízo "não tinha força para impedir que a Justiça apreciasse o pedido de confissão de falência por ser esta de ordem pública e contrariar o postulado constitucional da nulidade da lei que retirasse da apreciação judicial os direitos individuais” (FERREIRA, 1961, p. 43). A Lei 6.024/74, por sua vez, não tornou clara a opção pelo afastamento do regime falencial, ao dispor em seu art. $1^{\circ}$ que as instituições financeiras estarão sujeitas ao regime da liquidação extrajudicial ou à falência. A dúvida quanto à possibilidade de decretação da falência à revelia da atuação do Banco Central também se extraía do art. 36 da Lei 6.024/74, que inclui o termo "falência” ao se referir à indisponibilidade de bens dos administradores de instituições financeiras, bem como do art. 41 , $\S 1^{\circ}$, da mesma lei, ao indicar a abertura de inquérito pela comunicação do escrivão da falência. Assim, como se verifica em Coelho (2003, p. 398), havia na doutrina, antes da edição da Lei $n^{0}$ 11.101/2005, quem afirmasse a possibilidade de que a instituição financeira tivesse sua falência decretada judicialmente, caso não estivesse sob liquidação extrajudicial ou intervenção decretada pelo Banco Central. 
A opção legislativa pela prevalência do regime de liquidação extrajudicial, em relação às instituições financeiras, somente se mostrou incontroversa pela edição da Lei 11.101/2005, ao estabelecer não estarem sujeitas à sua incidência as instituições financeiras (art. 2º II).

No caso das operadoras de planos de saúde, nunca houve essa dúvida, mesmo antes da edição da Lei $n^{\circ}$ 11.101/2005. A redação original do caput do art. 23 da Lei 9.656/98 já previu que as operadoras de planos de saúde não se sujeitam à falência, ao estabelecer que essas entidades sujeitarse-iam apenas à liquidação extrajudicial prevista no Decreto-Lei 73/66. É de se recordar que à época da edição da Lei 9.656/98 as operadoras de planos de saúde estavam sob o poder de polícia da Superintendência de Seguros Privados - SUSEP, o que explica a referência apenas ao Decreto-Lei 73/66. O dispositivo foi alterado pela MP 1.908-18/99, para excluir a referência ao Decreto-Lei 73/66, e depois pela MP 2.097-40/2001, para excepcionar também a insolvência civil. O dispositivo possui atualmente a seguinte redação: “As operadoras de planos privados de assistência à saúde não podem requerer concordata e não estão sujeitas a falência ou insolvência civil, mas tão-somente ao regime de liquidação extrajudicial”.

A Lei 11.101/2005, em seu art. 2º II reiterou a exclusão das operadoras de planos de saúde do regime falencial. Vejamos, no entanto, que se trata de uma exclusão relativa do regime falencial, tendo em vista que a Lei $n^{\circ} 9.656 / 98$, em seu art. 23 , $\S \S 1^{\circ}$ e $3^{\circ}$, admite que o regime de liquidação extrajudicial venha a ser convertido em falência ou insolvência civil. A opção do legislador em afastar o regime falencial decorreu da extensão, às operadoras de planos de saúde, das mesmas condições de fiscalização e controle existentes para as seguradoras. É o que constatamos da seguinte passagem do relatório do deputado Pinheiro Landim, ao destacar os pontos principais do projeto de lei que tramitou na Câmara dos Deputados e que culminou na Lei nº 9.656/98:

$23^{\circ}$ ) a extensão às operadoras de planos das mesmas condições de fiscalização e controle existentes para as seguradoras, inclusive com a previsão de direção fiscal em casos de anormalidades econômico-financeiras, de liquidação extrajudicial em caso de insolvência e de aplicação de penalidades pecuniárias às operadoras e de inabilitação para seus administradores e correlatos; (BRASIL, Câmara dos Deputados, 1997, p. 31.608).

As consequências do afastamento relativo do regime falencial em relação às operadoras de planos de saúde são as seguintes: (i) o credor de uma operadora está impedido de formular pedido de decretação de falência da devedora; (ii) os administradores e sócios da operadora não podem requerer a autofalência ${ }^{4}$; e (iii) as sociedades operadoras de planos de saúde não têm direito à recuperação judicial ou extrajudicial.

\footnotetext{
${ }^{4}$ No caso das entidades sujeitas à insolvência civil, as duas primeiras consequências, relativas ao impedimento da instauração do concurso judicial, também são aplicáveis.
} 


\section{A QUESTÃO DA INAFASTABILIDADE DA JURISDIÇÃO}

A impossibilidade de que os credores e os sócios da operadora em crise econômicofinanceira se socorram da via judicial para formular o pedido de falência ou insolvência civil suscita a dúvida quanto à compatibilidade desse regime com a garantia da inafastabilidade da jurisdição.

A posição de Rubens Requião (1995) é bastante reveladora do cerne da controvérsia. Apesar de reconhecer que a admissibilidade da decretação da falência independentemente da liquidação extrajudicial provoca efeitos nefastos para a regulação do mercado financeiro, o emérito professor catedrático da Faculdade de Direito da Universidade Federal do Paraná se rendeu ao entendimento de que a inafastabilidade da jurisdição impediria a vedação ao acesso à via judicial da falência. O resultado desse entendimento é que qualquer credor pode "facilmente obstruir a atividade administrativa e intervencionista do Estado, requerendo a declaração de falência de empresa já posta em regime de intervenção administrativa ou liquidação extrajudicial” (REQUIÃO, 1995, p. 213). A controvérsia, portanto, reside em se adotar uma interpretação formalista ou consequencialista do princípio da inafastabilidade da jurisdição.

A atitude formalista trata os direitos constitucionais como "formas platônicas universalizadas e eternizadas ou como trunfos que superam automaticamente qualquer outra consideração” (POSNER, 2012, p. 248). Por sua vez, ressalta Aragão (2009, p. 11-30), a interpretação consequencialista se mostra como um critério para a escolha entre diversos caminhos hermenêuticos plausíveis, em que sobreleva a importância dos resultados concretos da aplicação da norma.

A adoção de uma interpretação formalista do princípio da inafastabilidade da jurisdição, na situação em análise, impediria que o legislador tutelasse de maneira eficiente valores constitucionalmente relevantes, como a proteção do consumidor e o adequado funcionamento do mercado regulado.

Os regimes especiais são medidas administrativas que têm por objetivo diminuir o impacto da quebra de uma operadora de planos de saúde. A preocupação primeira da Agência Reguladora é a adequada proteção da carteira de beneficiários da operadora em dificuldades. Assim, previamente à decretação da liquidação, serão adotadas sucessivas medidas protetivas buscando garantir a manutenção da assistência médica ou odontológica: a determinação da alienação voluntária ou compulsória da carteira (RN ANS nº 112/2005); fracassada a tentativa de alienação, a Agência permitirá a oferta pública das referências operacionais e do cadastro de beneficiários (RN-ANS $n^{\circ}$ 384/2015) ou concederá a portabilidade especial de carências (RN-ANS nº 186/2009, art. $7^{\circ}$-A). 
Mesmo inexistindo o risco imediato à carteira de beneficiários da operadora, a Agência permanece com o dever de acompanhar a saída ordenada da operadora do mercado de saúde suplementar, a fim de tutelar outros interesses relevantes - em especial os interesses dos credores assistenciais. A higidez do mercado de saúde suplementar é um elemento essencial para a manutenção do atendimento à saúde dos beneficiários de outras operadoras. Dessa forma, o risco à qualidade ou à continuidade do atendimento à saúde, indicado no art. 24 da Lei 9.656/98 como habilitador da atuação da Agência Reguladora por meio dos regimes especiais, não deve ser interpretado de forma restritiva, abrangendo apenas o atendimento dos beneficiários diretos da operadora sob intervenção, mas sim de forma ampla, para abranger todos os beneficiários do sistema que possam sofrer efeitos reflexos causados pela má administração de um dos participantes do mercado.

É preciso levar em consideração as consequências ao se interpretar a Constituição, ao menos quando elas se mostrem realmente muito ruins. Essa é a conclusão a que chega Sunstein (2009), ao analisar o comportamento da Corte constitucional diante da opinião pública. Por prudência, a reação adversa do público deve ser levada em consideração pelas Cortes quando possa produzir resultados excessivamente negativos. Destaca Sunstein:

O argumento consequencialista consiste em que, se uma decisão puder produzir efeitos terríveis, os juízes devem levar esses efeitos em conta. É tentador pensar que juízes devam julgar como lhes pareça melhor, mesmo que os céus caiam. Mas se os céus realmente caíssem, talvez os juízes não devessem julgar como lhes parecesse melhor. (SUNSTEIN, 2009, p. 141)

A intervenção judicial, seja pela concessão de recuperação extrajudicial ou pela decretação da falência de uma operadora, sem a prévia mediação da Agência Reguladora, desorganiza o sistema protetivo idealizado pelo legislador. Assim, a imediata tutela judicial pode resultar em grave dano ao mercado e aos consumidores da saúde suplementar, tendo em vista o déficit informacional do Judiciário sobre os elementos sistêmicos envolvidos e a ausência de meios judiciais adequados para conduzir o processo de solução da crise econômico-financeira da operadora. Essa consequência danosa não deve ser desconsiderada pelo intérprete, ao se buscar a adequada compreensão do princípio da inafastabilidade da jurisdição.

Observemos que a jurisprudência do Supremo Tribunal Federal tem buscado um ponto de equilíbrio na interpretação do princípio da inafastabilidade da jurisdição. Ao discutir o rito previsto na Lei n. 11.417/2006, que define os legitimados para a edição, revisão e cancelamento de enunciado

\footnotetext{
${ }^{5}$ Tradução livre. Original: "The consequentialist claim is that if a ruling would turn out to have terrible effects, judges should take those effects into account. It is tempting to think that judges should rule as they see fit even if the heavens would fall. But if the heavens really would fall, perhaps judges should not rule as they see fit.” (SUNSTEIN, 2009, p. 141).
} 
de súmula vinculante, o Supremo Tribunal Federal (Pet. 4.556-AgR) já consagrou que o exercício das garantias constitucionais do direito de petição e da inafastabilidade da apreciação do Poder Judiciário exigem a observância das regras processuais. De igual maneira, o Supremo Tribunal Federal (AO 1.531 AgR) já decidiu que o direito de petição e a inafastabilidade da jurisdição não garantem a quem não tenha capacidade postulatória litigar em juízo. Em outra ocasião, ao decidir sobre a constitucionalidade da exigência de prévio requerimento administrativo para o ajuizamento de ação previdenciária, o Supremo Tribunal Federal (RE 631.240), embora tenha ressaltado não ser exigível o exaurimento da via administrativa, reconheceu que a instituição de condições para o regular exercício do direito de ação é compatível com o art. 5, XXXV, da Constituição.

Assim, tendo em vista a necessidade de tutela efetiva da proteção do consumidor e do adequado funcionamento do mercado regulado, bem como a premissa de que a inafastabilidade da jurisdição não exime o postulante de cumprir as normas fixadas na lei processual, concluímos que o credor não tem direito à instauração do juízo universal da falência se a lei exclui sua legitimidade ou torna o pedido juridicamente impossível em determinadas circunstâncias. O núcleo intangível da inafastabilidade da jurisdição é a impossibilidade de que a lei prive o credor de meios efetivos para tutelar seu direito de crédito, mas isso não importa em reconhecer um direito fundamental a requerer a instauração da falência ou da insolvência civil.

Nessa perspectiva, vejamos que o art. 23 da Lei 9.656/98 e o art. $2^{\circ}$, II da Lei 11.101/2005, embora afastem a possibilidade de instauração imediata da falência, não proíbem que o credor se utilize dos meios executivos próprios para a satisfação de seu crédito. Mesmo depois da decretação da liquidação extrajudicial, o credor buscará a efetivação de seu direito de crédito perante a autoridade administrativa - por meio da declaração de créditos prevista no art. 22 da Lei $n^{0}$ 6.024/74. Havendo qualquer obstáculo à efetivação desse direito, o credor poderá se socorrer da tutela jurisdicional. A única restrição que lhe é imposta é a impossibilidade de formular o pedido de instauração da falência. De toda forma, se o concurso universal já fosse instaurado pela decretação da liquidação extrajudicial, o pedido judicial de falência não acrescentaria nada ao credor que já não lhe fosse assegurado na esfera administrativa.

A questão da constitucionalidade das restrições ao direito de ação nas liquidações extrajudiciais já foi debatida, de longa data, especificamente em relação ao efeito da decretação do regime especial de suspender as ações e execuções iniciadas sobre diretos e interesses relativos ao acervo da liquidanda, conforme prevê o art. 18, a, da Lei 6.024/74. Também o Decreto-Lei 73/66, prevê em seu art. 98, $a$, como efeito do ato de cassação (na verdade, de decretação da liquidação extrajudicial) a "suspensão das ações e execuções judiciais, excetuadas as que tiveram início 
anteriormente, quando intentadas por credores com privilégio sobre determinados bens da Sociedade Seguradora”. Por sua vez, a própria Lei 11.101/2005 dispõe que a decretação da falência suspende o curso de todas as ações e execuções em face do devedor, inclusive aquelas dos credores particulares do sócio solidário, mas terá prosseguimento no juízo no qual estiver se processando a ação que demandar quantia ilíquida (art. $6^{\circ}$, caput e $\S 1^{\circ}$ ).

A regra da suspensão das ações e execuções e do impedimento à propositura de quaisquer outras ações, enquanto durar a liquidação, não é necessariamente inconstitucional, mas exige a sua compatibilização com o princípio da inafastabilidade da jurisdição. Arnold Wald (1981, p. 10-11), baseado em antiga jurisprudência do Supremo Tribunal Federal (RE 75.409-GB), sustenta a constitucionalidade da intercalação da instância administrativa, isto é, do reconhecimento da existência de um verdadeiro contencioso administrativo que suspende temporariamente a apreciação da lesão ao direito individual. No referido precedente jurisprudencial, o Ministro Xavier de Albuquerque, condutor do voto vencedor, destacou que a liquidação extrajudicial não viola a garantia da inafastabilidade da jurisdição, na medida em que apenas consiste em uma intercalação da esfera administrativa. Essa fase administrativa não tem potencial de excluir da apreciação do Judiciário qualquer lesão a direito individual, uma vez que as ações individuais sobrestadas pela decretação do regime especial são retomadas após a decisão do recurso contra o julgamento das habilitações dos créditos, conforme previsto, à época, pelos arts. $6^{\circ}$ e 19 do Decreto-Lei 9.346/46 e atualmente pelo art. 27, da Lei ${ }^{\circ}$ 6.024/74.

Falciano aduz que “o propósito do artigo 18 ‘a’, da Lei 6.024/74 não é impedir o acesso ao Judiciário, mas impedir a cobrança individual dos créditos e, por conseguinte, viabilizar o regime concursal” (FALCIANO, 1999, p. 197). Segundo o referido autor, haveria um total esvaziamento do procedimento liquidatário se todas as demandas envolvendo credores na liquidação extrajudicial, como a impugnação à classificação dos créditos e os pedidos de restituição, pudessem ser, desde logo, apreciados pelo Judiciário, com fundamento na inafastabilidade da jurisdição. Dessa forma, conclui Rogério Falciano: “O ajuizamento de qualquer ação em face dos atos oriundos da Lei n 6.024/74 não pode olvidar de sua natureza indivisível e universal” (FALCIANO, 1999, p. 197-198).

No entanto, para compatibilizar a regra da suspensão das ações com a inafastabilidade da jurisdição, já decidiu o Superior Tribunal de Justiça que a literalidade do art. 18, a, da Lei 6.024/74 deve ser abrandada quando a continuidade do processo de conhecimento não redundar em qualquer redução do acervo patrimonial da liquidanda (REsp 717166/PE). O credor de quantia ilíquida poderá propor sua ação individual, para obter a certeza e a liquidez de seu crédito, independentemente de sua faculdade de declarar o crédito perante o liquidante, uma vez que aquela ação de conhecimento não 
atenta contra a natureza indivisível e universal da liquidação extrajudicial. Uma vez obtido o título executivo judicial, o credor não poderá prosseguir em sua execução individual e deverá ser incluído no quadro de credores. Portanto, a norma do art. $6^{\circ}$, § $1^{\circ}$, da Lei 11.101/2005 é também aplicável às liquidações extrajudiciais, pelo que podemos concluir que o credor de obrigação ilíquida poderá tanto somente habilitar seu crédito, seja na liquidação extrajudicial, na falência ou na insolvência civil, quanto prosseguir na ação de conhecimento individual ou propor essa ação para obter a certeza e liquidez do seu crédito a ser posteriormente incluído no quadro de credores.

O Superior Tribunal de Justiça (REsp 40712/RS) já afirmou, com base na regra da suspensão das ações do art. 18, $a$, da Lei 6.024/74, a impossibilidade do pedido de falência formulado pelo sócio de instituição financeira. No entanto, mesmo antes da decretação da liquidação extrajudicial momento em que não se poderia invocar a regra do art. 18, $a$, da Lei 6.024/74 - o pedido de falência ou insolvência civil formulado diretamente pelos administradores ou sócios da operadora de planos de saúde deve ser rejeitado pela ausência de pressuposto processual extrínseco, qual seja, a decretação da liquidação extrajudicial seguida da autorização da ANS para que o liquidante formule o pedido. É preciso conjugar o art. 105 da Lei 11.101/2005 e o art. 759 do Código de Processo Civil de 1973 (mantido em vigor pelo art. 1.052 da Lei $\mathrm{n}^{\circ}$ 13.105/2015), que atribuem ao devedor a legitimidade para requerer a autofalência e a autoinsolvência civil, com o art. 23, § $1^{\circ}$, da Lei 9.656/98, que estipula ser possível a falência ou insolvência de operadora de planos de saúde somente por iniciativa do liquidante, devidamente autorizado pela ANS, diante da constatação de uma das hipóteses arroladas na lei especial.

Do ponto de vista dos sócios e administradores da operadora, a constitucionalidade da proibição da formulação do pedido de autofalência é condicionada à existência de um meio alternativo a possibilitar o encerramento da atividade empresarial: a decretação da liquidação extrajudicial a pedido. A plena possibilidade de controle jurisdicional sobre essa via administrativa alternativa à autofalência é suficiente para garantir o respeito à inafastabilidade da jurisdição.

Por outro lado, as operadoras de planos de saúde não têm direito, ainda, à recuperação judicial ou extrajudicial, uma vez que à época da edição da Lei de Falências e Recuperação de Empresas estavam proibidas de requerer concordata, nos termos do art. 23, caput, da Lei 9.656/98. Assim, incide primeiramente a vedação constante do art. 198 da Lei 11.101/2005. Não bastasse a vedação do artigo supramencionado, o impedimento à concessão de recuperação judicial ou extrajudicial já se extrai do art. $2^{\circ}$, II, da Lei 11.101/2005, que exclui a incidência da Lei de Falências e Recuperação de Empresas às operadoras de planos de saúde. Lima e Fonseca (2009, p. 1.312-1.313), no entanto, destacam a intencionalidade da redundância do art. 198 da citada lei, a fim de afastar 
qualquer interpretação inadequada da norma, que pretendesse sustentar a aplicação das disposições relativas à recuperação judicial ou extrajudicial às entidades submetidas à liquidação extrajudicial.

A incidência subsidiária (ou aplicação remissiva) da Lei 11.101/2005 ao regime de liquidação extrajudicial não importa na possibilidade de concessão de recuperação judicial ou extrajudicial de operadoras de planos de saúde, uma vez que essas empresas estavam impedidas de requerer a concordada na data da edição da Lei de Falências. Assim, a jurisprudência tem afirmado que "não se deve permitir o processamento da recuperação judicial de sociedade operadora de plano de saúde quando há expressa vedação legal nesse sentido e quando o procedimento para tal tipo de pessoa jurídica é regulamentado por agência reguladora” (ESPÍRITO SANTO, 2015).

Os procedimentos visando à recuperação das operadoras de planos de saúde seguem as regras estabelecidas pela ANS, editadas no exercício do seu poder normativo para fixar as normas sobre o funcionamento das operadoras, incluindo procedimentos de recuperação financeira (Lei 9.961/2001, art. $4^{\circ}$, XLI, e). O tema se encontra disciplinado pela Resolução Normativa ANS $n^{\circ}$ 307/2012, que dispõe sobre os Procedimentos de Adequação Econômico-Financeira - PAEF, bem como pelos arts. $8^{\circ}$ a 11 da Resolução Normativa ANS n 316/2012, que dispõe sobre o Programa de Saneamento no curso do regime de direção fiscal.

É certo que tanto o Plano de Adequação Econômico-Financeira - PLAEF - quanto o Termo de Assunção de Obrigações Econômico-Financeiras - TAOEF -, mecanismos regulatórios previstos para a recuperação das operadoras, são institutos de eficácia limitada. Essa situação já era identificada em relação à recuperação das instituições financeiras, cujos instrumentos de recuperação dependiam da atuação unilateral das instituições proponentes, antes do advento da Lei 9.447/97, que dotou o Banco Central “de instrumentos hábeis sob cujo fundamento pudesse determinar medidas de capitalização da empresa, de reorganização societária, de transferência de controle ou de afastamento de administradores” (SIQUEIRA, 2001, p. 69). Nesse aspecto, podemos observar que a ausência de expressa menção da Lei 9.447/97 no art. 24-D da Lei nº 9.656/98 deixou o ordenamento da saúde suplementar carente de instrumentos adequados de regulação de caráter prudencial, como aqueles previstos no art. $6^{\circ}$ da Lei 9.447/97. Ocké-Reis (2012, p. 140) alerta, inclusive, que a ausência de mecanismos regulatórios efetivos visando à recuperação de operadoras em crise pode resultar em uma acelerada concentração de mercado, por meio do crescimento do número de liquidações extrajudiciais na saúde suplementar.

Estando as operadoras de planos de saúde ordinariamente excluídas do regime falencial e da decretação da insolvência civil, a crise econômico-financeira dessas empresas é causa para a instauração do regime especial de liquidação extrajudicial. 


\section{A QUESTÃO DA SEPARAÇÃO DE PODERES}

A ideia de uma intercalação da esfera administrativa pode suscitar questionamentos quanto ao respeito ao princípio da separação de poderes. Em uma visão muito estreita desse princípio, poderíamos perquirir se a lei estaria atribuindo, de forma indevida, funções tipicamente jurisdicionais a órgãos da Administração Pública. Para afastar esse questionamento, vejamos, de forma mais cuidadosa, a natureza da liquidação extrajudicial e a possibilidade de exercício de funções quasejudiciais por órgãos da Administração Pública.

\subsection{A NATUREZA DA LIQUIDAÇÃO EXTRAJUDICIAL: INTERVENÇÃO ADMINISTRATIVA NO DOMÍNIO ECONÔMICO}

A liquidação extrajudicial de operadoras de planos privados de assistência à saúde é uma medida administrativa decretada de ofício ou a pedido dos administradores da operadora, visando ao encerramento de suas atividades, mediante ato de dissolução e processo de liquidação do patrimônio, pagamento dos credores e extinção da pessoa jurídica, em função do não saneamento de anormalidades econômico-financeiras ou administrativas graves, de violação grave das normas regulatórias ou, ainda, em razão da aplicação de sanção administrativa de cancelamento da autorização de funcionamento ou do registro provisório.

Aduz Bessone que “a expressão 'liquidação extrajudicial’ é insuficiente, porque, apenas, precisa que a liquidação se faz fora do juízo, mas não indica o caráter de liquidação forçada administrativa, que é o que verdadeiramente sobreleva” (BESSONE, 1995, p. 206). Para Bessone (1995, p. 206), a liquidação extrajudicial é uma liquidação forçada de natureza administrativa ${ }^{6}$.

Embora guarde estreita analogia com a falência, com a insolvência civil e também com a liquidação societária ordinária, a liquidação extrajudicial não se confunde com nenhum desses institutos. A liquidação administrativa, mesmo a voluntária (a pedido da operadora), não se confunde com a liquidação ordinária, prevista nos arts. 1.102 a 1.112 do Código Civil e nos arts. 208 a 219 da Lei 6.404/76. A liquidação ordinária de operadoras de planos de saúde, apesar de se processar mediante autorização da ANS (art. 8º $§ 3^{\circ}$, da Lei 9.656/98), é desenvolvida pelos administradores e sócios da operadora. A escolha do liquidante segue, na liquidação ordinária, as normas da lei societária: se a indicação não constar do estatuto social, a escolha do liquidante será feita pelos sócios

\footnotetext{
${ }^{6}$ No entanto, não se deve esquecer que a liquidação extrajudicial pode ser decretada a pedido dos administradores da operadora (RN-ANS 316/2012, art. 17, § 2º Lei 6.024/74, art. 15, II; Decreto-Lei 73/66, art. 94, a).
} 
(art. 1.038 do Código Civil e art. 208 da Lei 6.404/76). Já a liquidação extrajudicial é processada à revelia da vontade ou, melhor seria dizer, em substituição à vontade dos administradores ou sócios da operadora. Ainda que se trate de liquidação extrajudicial provocada, a participação dos sócios e administradores se dá apenas na formulação do pedido de decretação do regime, mas todo o processo se desenvolve por iniciativa da Administração.

Bessone aponta que “mesmo recorrendo a regras falenciais, as liquidações extrajudiciais não se revestem de caráter mercantil ou, mais precisamente, falimentar” (BESSONE, 1995, p. 207). Na verdade, conforme ressalta Requião (1995, p. 200-2001), trata-se de uma forma sui generis de liquidação, configurando um instituto típico de Direito Administrativo Econômico, com repercussão no Direito Societário e no Direito Falencial.

A liquidação extrajudicial difere da falência e da insolvência civil porque tanto no concurso falimentar quanto no concurso civil estão em jogo, em primeiro plano, os interesses privados. É certo que na falência também há tutela do interesse público, por meio do saneamento do ambiente empresarial e da garantia da par conditio creditorum, elementos essenciais à proteção do crédito, como ressalta Campinho (2010, p. 7-8). A execução individual é feita no interesse do credor penhorante e, mesmo diante de vários credores e sucessivas penhoras, a satisfação dos credores, na ausência de direitos de preferência, é feita segundo a anterioridade de cada penhora (art. 908, § $2^{\circ}$ do Código de Processo Civil). Diversa é a situação quando se instaura uma execução coletiva abrangendo a totalidade dos credores (universalidade subjetiva) e a totalidade dos bens do devedor (universalidade objetiva). Nessa situação, tal como ocorre na falência, “arrecada-se o patrimônio disponível do devedor, garantia comum dos credores, e congregam-se todos estes, para a defesa coletiva de seus direitos e interesses” (MENDONÇA, 2005, p. 24). O princípio par conditio creditorum consiste no dever de que o Estado, diante da arrecadação de todo o patrimônio e da convocação de todos os credores, assegure o tratamento igualitário dos credores da mesma classe.

A liquidação administrativa, todavia, é construída imediatamente visando à saída ordenada da operadora do mercado e apenas mediatamente atua na garantia dos interesses dos credores. É o que se colhe da lição de Waldemar Ferreira, senão vejamos:

Estudando a natureza da liquidação extrajudicial, em face da falência, de que é instituto afim,
doutrinou FRANCESCO FERRARA que a falência se propõe à satisfação dos credores em
caso de insolvência. A liquidação coacta administrativa se propõe em vez à eliminação da
empresa do mercado; ou, quando a liquidação da empresa é inevitável por seu estado de ruína,
que a mesma se torne compatível com o interesse público. Tem-se destarte, finalidade
squisitamente pubblica, que pode consistir, ou na eliminação da empresa do mercado ou no
modo pelo qual se lhe conduzirá a liquidação. Por certo, a liquidação da empresa se destina
necessariamente à satisfação dos credores, mas este aspecto é conseqüência, está em segundo
plano, a despeito de que, teoricamente, ao sentir do expositor, se possa ter liquidação coacta 
administrativa ainda que não existam credores, o que, é de acrescentar, é incondizente com a falência. (FERREIRA, 1961, p. 46).

A atividade de saúde suplementar é uma atividade privada de interesse público inserida em um regime jurídico diferenciado. Hentz e Diniz (2004, p. 29-30) ressaltam que o interesse estratégico e a ampla repercussão social fazem com que algumas atividades dependam de fiscalização estatal desde o início do seu funcionamento até a extinção da sociedade empresária. Esse regime especial, como indica Requião (1995, p. 200-2001), manifesta-se, portanto, também no momento do encerramento das atividades da empresa. A liquidação extrajudicial, sob esse prisma, é uma medida administrativa de intervenção no domínio econômico, fundada no interesse público de manutenção da continuidade e da qualidade do atendimento à saúde proporcionada pela atividade privada de operação de planos de saúde. É o que já reconheceu o Superior Tribunal de Justiça, em relação à liquidação extrajudicial de instituições financeiras, em acórdão relatado pelo ministro Luiz Fux, em que se afirmou: “a atribuição conferida ao Banco Central pela Lei $n^{\circ}$ 6.024, de 1974, para decretar a liquidação extrajudicial de instituições financeiras constitui efetivo instrumento de intervenção do Estado no domínio econômico, manifestação do poder de polícia exercido pela autarquia” (REsp 930970/SP). Assim, em que pesa sua complexidade jurídica, por suscitar questões de Direito Público e Privado, trata-se do exercício de uma função tipicamente administrativa.

\subsection{O EXERCÍCIO DE FUNÇÕES QUASE-JUDICIAIS POR ÓRGÃOS DA ADMINISTRAÇÃO PÚBLICA}

A decretação da liquidação extrajudicial pode resultar na formação de um concurso de credores, perante a autoridade administrativa, quando houver habilitação de credores. De uma forma geral, seguir-se-á que os bens integrantes do patrimônio da sociedade liquidanda serão arrecadados e vendidos em hasta pública; os credores serão convocados para a habilitação de seus créditos; o liquidante decidirá quanto à legitimidade, valor e classificação dos créditos apresentados; a ANS decidirá as impugnações apresentadas e os recursos contra as decisões do liquidante; e o produto da venda do patrimônio será entregue aos credores para a satisfação das obrigações da sociedade liquidanda. Durante toda essa tramitação, as ações sobre direitos e interesses relativos ao acervo da entidade liquidanda estarão suspensas e os credores não poderão ajuizar novas ações, salvo as exceções legais.

Anotam Ferreira (1961, p. 43) e Miranda (2003, p. 131-132) que esse conjunto de atos que se processam perante a autoridade administrativa consiste em um processo executivo concursal substitutivo da atividade jurisdicional. O Superior Tribunal de Justiça já reconheceu que a liquidação 
extrajudicial dos bancos, na forma da Lei $n^{\circ}$ 6.024/74, tem natureza de execução coletiva (EDcl no REsp 502336/CE). No julgado em questão, atribuíram-se os mesmos efeitos da decretação da falência à liquidação extrajudicial, a possibilitar a penhora no rosto dos autos do processo de liquidação extrajudicial para a satisfação de crédito tributário, em respeito à ordem de preferência. Trata-se da aplicação, à liquidação extrajudicial, da parte final do enunciado $n^{\circ} 44$ do extinto TFR:

Ajuizada a execução fiscal anteriormente à falência, com penhora realizada antes desta, não ficam os bens penhorados sujeitos a arrecadação no Juízo falimentar; proposta a execução fiscal contra a massa falida, a penhora far-se-á no rosto dos autos do processo da quebra, citando-se o síndico.

Sendo a liquidação administrativa um processo de execução, o liquidante é um órgão da execução forçada, na expressão de Miranda (2003, p. 114) ou o órgão executor da liquidação extrajudicial, como prefere Faria (1985, p. 26). A ANS, por sua vez, é o órgão que preside e dirige o processo de liquidação. Esses dois órgãos assumem, dessa forma, a posição correspondente ao administrador judicial e ao juiz na falência, conforme expressamente prevê o art. 34 da Lei 6.024/74.

A liquidação extrajudicial é, portanto, um equivalente da atividade jurisdicional. Evidentemente que, como todo equivalente jurisdicional, a liquidação extrajudicial não tem o caráter de definitividade, uma vez que todas as decisões tomadas na esfera administrativa estão sujeitas à revisão jurisdicional.

A atribuição conferida ao liquidante para decidir sobre a legitimidade, o valor e a classificação dos créditos declarados na liquidação (art. 23 da Lei 6.024/74) e a atribuição da ANS para decidir sobre a impugnação dos demais credores à legitimidade, valor e classificação dos créditos (art. 26 da Lei 6.024/74) é, provavelmente, a visualização mais clara da liquidação extrajudicial como um equivalente jurisdicional. Conforme destaca Bessone (1995, p. 217-218), essas decisões administrativas não usurpam a função jurisdicional, na medida em que estarão sujeitas ao controle judicial em caso de lesão ou ameaça de lesão a direito subjetivo de qualquer credor (RN-ANS 316/2012, art. 42; Lei 6.024/74, art. 27; DL 73/66, art. 103).

Em suma, a liquidação extrajudicial é uma atividade tipicamente administrativa de intervenção no domínio econômico. No âmbito do direito processual, a liquidação extrajudicial se caracteriza como um processo executivo concursal perante autoridade administrativa, substitutivo da atividade jurisdicional (equivalente jurisdicional), com repercussões nas relações jurídicas privadas, como aquelas envolvendo os credores e a operadora liquidanda.

No sistema financeiro o modelo administrativo de liquidação de bancos foi introduzido no Brasil logo após a Revolução de 1930. A adoção, a partir de 1996, do modelo de agências reguladoras 
independentes, responsáveis por implementar a regulação econômica e social em áreas sensíveis, trouxe maior visibilidade para essas novas funções administrativas (funções quase-judiciais). De fato, afirma Marques Neto (2003, p. 26) que a regulação, como atividade da Administração, abrange um híbrido de funções de variada natureza e se manifesta por meio de atos de regulação - poderes quaselegislativos, quase-judiciais e executivos. Por isso, como aponta Möllers (2013, p. 121-126), os entes reguladores, em especial as agências reguladoras independentes, não se enquadram com facilidade no modelo de rígida separação de poderes. Essa forma de atuação administrativa produz efeitos sobre o modelo de separação de poderes. No entanto, tenhamos em vista que esse não é um processo histórico novo.

Cappelletti (1993, p. 43-56) e Moncada (2002, p. 98-110) ressaltam que, desde a implantação do Estado Social, o princípio da separação de poderes sofreu grande impacto pelo agigantamento do ramo administrativo (e também pelo judicial) do Estado, em detrimento do ramo legislativo. Assim, destacam Bonavides (2014, p. 86) e Guastini (2007, p. 53-77), a rígida separação de funções, então baseada na especialização e na independência, cede lugar a um modelo de maior colaboração e vinculação entre os poderes, por meio de um complexo sistema de checks and balances, em que as funções, embora divididas, encontram-se distribuídas em uma pluralidade de órgãos, que, longe de serem independentes, dispõem de meios de controle e influência recíprocos. Por outro lado, a proliferação de novos centros de poder e instituições, que não se adequam ao modelo clássico, levou Bruce Ackerman a propor o abandono do modelo tradicional de tripartição de poderes, "para levar em conta um mundo institucional em que instituições independentes desempenham funções cada vez mais importantes - apesar de não poderem ser classificadas como legislativas, judiciais ou executivas” (ACKERMAN, 2014, p. 19).

Aduz Melo (2013, p. 216-217) que o princípio da separação de poderes, enquanto postulado de organização política das funções do Estado, é marcado pelas circunstâncias históricas e sociais. Disso concluímos que o argumento da violação da separação de poderes, em decorrência da atribuição de funções à Administração Pública para proceder à liquidação extrajudicial de operadoras de planos de saúde, em substituição à atividade jurisdicional, está apegado a uma visão estreita e ultrapassada do princípio. Essa inadmissível compreensão da separação de poderes idealiza um sistema de rígida divisão de funções entre os poderes e não compreende as novas atribuições que os entes da Administração Pública passaram a exercer para dar conta da realidade das sociedades modernas complexas, com seus novos problemas e desafios. 


\section{A CONVERSÃO DA LIQUIDAÇÃO EXTRAJUDICIAL EM FALÊNCIA OU INSOLVÊNCIA CIVIL}

As operadoras de planos de saúde se sujeitam à liquidação extrajudicial, mas não de forma absoluta, uma vez que o regime especial poderá ser convertido em falência ou insolvência civil. Por essa razão, a liquidação extrajudicial deve ser vista como uma intercalação da esfera administrativa, isto é, como uma fase prévia que não excluiu a esfera judicial.

Notemos que a possibilidade de utilização da via da insolvência civil, ao invés da falência, decorre do fato de que estão sujeitas à regulação não apenas sociedades empresárias, mas também cooperativas médicas e odontológicas e entidades filantrópicas e de autogestão, as quais podem assumir formas associativas ou mesmo fundacionais. Assim, a definição sobre o tipo de concurso universal a ser instaurado na esfera judicial - se falência ou insolvência civil - depende da natureza jurídica da operadora de planos de saúde, uma vez que a Lei $n^{\circ}$ 11.101/2005 restringe a falência apenas ao empresário e à sociedade empresária (art. $1^{\circ}$ ). É verdade, no entanto, que em relação às cooperativas há sensível controvérsia na doutrina quanto à sujeição ou não do regime falencial. Para alguns, a cooperativa, “ao adotar a prática mercantil de um produto (no caso, de planos de saúde) oferecido a terceiros, se equipara às demais sociedades comerciais e, portanto, sujeita[-se] àquele instituto [da falência]" (CUNHA, 2003, p. 168). No entanto, outros autores têm destacado que "as cooperativas em geral não se acham sujeitas à NFL [Nova Lei de Falências], ex vi do parágrafo único do art. 982 do Código Civil, que as considera simples e não empresárias” (DE LUCCA, 2009, p. 55). A jurisprudência, por sua vez, tem entendido que as cooperativas operadoras de planos de saúde se sujeitam à insolvência civil, aplicando-se, subsidiariamente, as normas falimentares (SÃO PAULO, 2017). Situação peculiar pode ocorrer diante da decretação de liquidação extrajudicial por extensão, na forma do art. 51 da Lei $n^{0}$ 6.024/74, quando a liquidanda principal é uma cooperativa e as liquidandas por extensão são sociedades empresárias. Nessa hipótese, em que a cooperativa liquidada e as demais empresas liquidadas por extensão se sujeitam a ritos distintos de falência ou insolvência civil, aponta a Resolução Normativa da ANS n 316/2012, art. 24, § 7º que deverá o liquidante requerer a conversão de todas as liquidações em falência.

Para converter a liquidação em concurso judicial, a ANS deverá autorizar o liquidante a formular o pedido de falência ou insolvência civil, quando constatar a existência de uma das hipóteses arroladas no $§ 1^{\circ}$ do art. 23 da Lei 9.656/98, conforme se verá mais adiante.

Muito embora o art. $2^{\circ}$, II, da Lei $\mathrm{n}^{\circ} 11.101 / 2005$ não tenha ressalvado a possibilidade de decretação da falência quando o pedido for formulado pelo liquidante, devidamente autorizado pela ANS, a doutrina, como se verifica em Coelho (2007, p. 197-198) e em Pitombo (2007, p. 105), e 
também a jurisprudência (MINAS GERAIS, 2010; SÃO PAULO, 2011), destacam que a Lei $n^{\circ}$ 11.101/2005, nesse particular, em nada alterou a sistemática da Lei 9.656/98. De fato, a exclusão do regime falencial é apenas relativa, uma vez que as operadoras de planos de saúde estarão sujeitas à falência ou à insolvência civil quanto o liquidante constatar a inviabilidade de prosseguimento da liquidação extrajudicial e solicitar autorização da ANS para formular o pedido de decretação da falência ou da insolvência civil.

No ordenamento setorial do mercado financeiro, a doutrina também aponta o caráter relativo do afastamento do regime falencial. Abrão, por exemplo, ressalta que somente o liquidante está legitimado a requerer a falência, após a instauração da liquidação extrajudicial, e ressalta que diante de situação patrimonial altamente deficitária ou diante de fortes indícios de crimes falimentares, "não há alternativa senão requerer a falência” (ABRÃO, 2011, p. 336). Requião (1995, p. 234) indica que a solução falimentar suplanta a liquidação extrajudicial se a insolvência for evidente e grave, isto é, se configuradas as hipóteses legais para a autorização do pedido de falência. Bessone (1995, p. 220221), por sua vez, aduz que não se pode descartar completamente uma análise subjetiva do Banco Central para autorizar o pedido de falência, mas ressalta que essa subjetividade não se manifesta na hipótese objetiva da insuficiência do ativo para cobrir pelo menos 50\% do passivo. Mendonça, ao interpretar o parágrafo único do art. 21 da Lei ${ }^{\circ}$ 6.024/74, que faz referência aos “pedidos formulados pelos interessados”, traz à tona a discussão quanto à “possibilidade de os interessados solicitarem ao Banco Central autorização para que seja requerida a falência da instituição, ou mesmo requererem a falência em juízo” (MENDONÇA, 2007, p. 235). Entendemos, no entanto, que o efeito da decretação da liquidação extrajudicial, de suspensão e impedimento de ajuizamento de novas ações sobre o acervo da entidade liquidanda (art. 18, a, da Lei 6.024/74), é um obstáculo ao pedido de falência formulado diretamente por um credor da instituição financeira.

Destaquemos, ainda, que a Lei $\mathrm{n}^{0}$ 13.506, de 13 de novembro de 2017, resultante da conversão da Medida Provisória $\mathrm{n}^{\circ}$ 784, de 7 de junho de 2017, introduziu significativa inovação jurídica, ao modificar a redação do art. 19 da Lei $n^{0}$ 6.024/74, para prever a possibilidade de que $o$ Banco Central encerre a liquidação extrajudicial, sem a necessidade de formular o pedido de falência, nos seguintes casos: pagamento integral dos credores quirografários; mudança de objeto social da instituição para atividade econômica não integrante do Sistema Financeiro Nacional; transferência do controle societário da instituição; convolação em liquidação ordinária; exaustão do ativo da instituição, mediante a sua realização total e a distribuição do produto entre os credores, ainda que não ocorra o pagamento integral dos créditos; ou iliquidez ou difícil realização do ativo remanescente na instituição, reconhecidas pelo Banco Central do Brasil. 
No caso das operadoras de planos de saúde, a primeira hipótese de conversão da liquidação extrajudicial em falência é quando o ativo da liquidanda não for suficiente para o pagamento dos créditos extraconcursais, dos créditos preferenciais e de pelo menos a metade dos créditos quirografários. O que se exige é que o ativo seja suficiente para o pagamento até a metade dos quirografários, pois esses credores só podem ser pagos após os credores das classes anteriores, arrolados no art. 83 da Lei 11.101/2005.

Também prevalece o regime falencial diante de indícios de crimes falimentares, especialmente por conta do que dispõe o art. 180, da Lei $\mathrm{n}^{\circ}$ 11.101/2005: “A sentença que decreta a falência, concede a recuperação judicial ou concede a recuperação extrajudicial de que trata o art. 163 desta Lei é condição objetiva de punibilidade das infrações penais descritas nesta Lei”. Sendo a sentença de decretação da falência condição objetiva de punibilidade dos crimes falimentares, a sua ausência torna inviável a persecução criminal pela prática de conduta tipificada como crime falimentar, como destaca Pitombo (2007, p. 570-571).

Por fim, a ANS deve autorizar o pedido de falência ou insolvência civil se o ativo realizável ${ }^{7}$ da liquidanda não for suficiente, sequer, para o pagamento das despesas administrativas e operacionais inerentes ao regular processamento da liquidação extrajudicial. A situação retrata um estado de insolvência tão grave que importa na completa ausência de perspectiva de pagamento dos credores, não se justificando a manutenção do processo na esfera administrativa.

\section{CONCLUSÕES}

A Lei $n^{\circ}$ 9.656/98, ao regular a atividade de operação de planos privados de assistência à saúde, dotou o órgão regulador de mecanismos próprios de intervenção e controle da atividade privada.

A imediata intervenção judicial nos momentos de crise econômico-financeira das operadoras de planos de saúde sem a prévia atuação da Agência Reguladora - autarquia dotada de especialização técnica e munida de informações estratégicas sobre o mercado de saúde suplementar - pode colocar em risco o interesse público específico de garantir a manutenção da qualidade e da continuidade da assistência à saúde aos beneficiários. Essa situação justifica o afastamento relativo, adotado pelo legislador, do regime falencial.

\footnotetext{
${ }^{7}$ A Resolução Normativa ANS n 316/2012, em seu art. 33, § 4º estabelece: “Considera-se ativo realizável como sendo todo ativo que possa ser convertido em moeda corrente em prazo compatível com o pagamento das despesas administrativas e operacionais da liquidanda”.
} 
A prevalência, circunstancial e transitória, da liquidação extrajudicial sobre a falência ou insolvência civil - que deve ser entendida apenas como uma intercalação da esfera administrativa não é incompatível com a inafastabilidade da jurisdição. O exercício do direito de ação está sujeito às restrições estabelecidas em lei. A intercalação da esfera administrativa, por si só, não representa a privação aos credores de medidas que assegurem a eficiente tutela de seus direitos. Mesmo as decisões administrativas sobre o direito dos credores não violam a inafastabilidade da jurisdição, na medida em que não são decisões definitivas. Ademais, o ato de julgar não é exclusivo do Poder Judiciário; específico do Judiciário é o caráter definitivo de seus pronunciamentos e a apreciação de temas que a Constituição ou as leis sujeitam à reserva de jurisdição.

A liquidação extrajudicial é uma atividade tipicamente administrativa de intervenção no domínio econômico, caracterizando-se como um processo executivo concursal perante autoridade administrativa, substitutivo da atividade jurisdicional. A atribuição de competência à Agência Reguladora para instaurar o concurso geral de credores, arrecadar os bens e proceder à liquidação de operadora de planos de saúde é manifestação dos poderes quase-judiciais da função regulatória exercida pela ANS sobre o mercado de saúde suplementar. O exercício dessas funções pela Administração Pública exige a devida compreensão da historicidade da separação de poderes, de maneira a permitir a adaptação do princípio às novas funções acometidas aos entes da Administração Pública nas sociedades contemporâneas complexas. De toda forma, embora a liquidação extrajudicial seja um instituto que afasta o regime falencial, não há qualquer invasão da esfera própria do Poder Judiciário.

Como consequência do afastamento do regime falencial, as operadoras de planos de saúde estão impedidas de requerer a recuperação judicial ou a autofalência e os credores da operadora não podem formular, em juízo, o pedido de falência. O mesmo se aplica às operadoras sujeitas à insolvência civil, tendo em vista o afastamento da esfera judicial, em um primeiro momento, em favor da prevalência da liquidação extrajudicial. Esse regime jurídico especial a que se sujeitam as operadoras de planos de saúde está relacionado à adoção do instituto da liquidação extrajudicial. Se o prosseguimento da liquidação extrajudicial for inviável, as operadoras de planos de saúde estarão sujeitas à falência ou à insolvência civil.

Assim, o art. $2^{\circ}$, II, da Lei $n^{0} 11.101 / 2005$, que exclui a aplicação da lei de falências às operadoras de planos de saúde, e o art. 23, § $1^{\circ}$, da Lei $n^{\circ} 9.656 / 98$, ao indicar que essas mesmas operadoras estão sujeitas ao regime de falência ou insolvência civil, exigem uma interpretação sistemática: as entidades se sujeitam ao regime falencial ou de insolvência civil se o pedido do 
liquidante para requerer a instauração do concurso judicial de credores for autorizado pela ANS. Portanto, a autorização da ANS é um requisito indispensável à decretação da falência ou insolvência civil das operadoras de planos de saúde.

A adequada interpretação da garantia da inafastabilidade da jurisdição e do princípio da separação de poderes, conforme demonstramos ao longo do artigo, permite concluir que não há, no sistema escolhido pelo legislador de intercalação da esfera administrativa, qualquer ofensa à ordem constitucional.

\section{REFERÊNCIAS}

ABRÃO, Nelson. Direito Bancário. São Paulo: Saraiva, 2011.

ACKERMAN, Bruce. Adeus, Montesquieu. Revista de direito administrativo, Rio de Janeiro, vol. 265, p. 13-23, jan./abr. 2014.

ALVES, Sandro Leal. Fundamentos, regulação e desafios da saúde suplementar no Brasil. Rio de Janeiro: Funenseg, 2015.

ARAGÃO, Alexandre Santos de. Interpretação consequencialista e análise econômica do direito público à luz dos princípios constitucionais da eficiência e da economicidade. Interesse Público IP, Belo Horizonte, ano 11, n. 57, p. 11-30, set./out. 2009.

ASIMOW, Michael. Cinco modelos de adjudicação administrativa (Justiça Administrativa). Revista de Investigações Constitucionais, Curitiba, vol. 4, n. 1, p. 129-165, jan./abr. 2017.

BESSONE, Darcy. Instituições de Direito Falimentar. São Paulo: Saraiva, 1995.

BONAVIDES, Paulo. Do Estado Liberal ao Estado Social. 11. ed. 2. tiragem. São Paulo: Malheiros, 2014.

BRASIL. Câmara dos deputados. Diário da Câmara dos Deputados, Brasília, 8 out. 1997.

BRASIL. Superior Tribunal de Justiça. Primeira Turma. Embargos de Declaração no Recurso Especial 502336/CE. Brasília: Diário da Justiça, 19 dez. 2003.

BRASIL. Superior Tribunal de Justiça. Primeira Turma. Recurso Especial 930970/SP. Brasília: Diário da Justiça Eletrônico, 3 nov. 2008.

BRASIL. Superior Tribunal de Justiça. Quarta Turma. Recurso Especial 40712/RS. Brasília: Diário da Justiça, 26 ago. 1996.

BRASIL. Superior Tribunal de Justiça. Segunda Turma. Recurso Especial 717166/PE. Brasília: Diário da Justiça, 21 nov. 2005. 
BRASIL. Supremo Tribunal Federal. Plenário. Agravo Regimental na Ação Originária 1.531. Brasília: Diário da Justiça Eletrônico, 1 jul. 2009.

BRASIL. Supremo Tribunal Federal. Plenário. Petição 4.556 em Agravo Regimental. Brasília: Diário da Justiça Eletrônico, 21 ago. 2009.

BRASIL. Supremo Tribunal Federal. Plenário. Recurso Extraordinário 631240. Brasília: Diário da Justiça Eletrônico, 10 nov. 2014.

BRASIL. Supremo Tribunal Federal. Segunda Turma. Recurso Extraordinário 75409-GB. Brasília: Diário da Justiça, 20 set. 1974.

CAMPINHO, Sérgio. Falência e Recuperação de Empresa: o novo regime de insolvência empresarial. 5. ed. Rio de Janeiro: Renovar, 2010.

CAPPELLETTI, Mauro. Juízes Legisladores? Porto Alegre: Sergio Antonio Fabris Editor, 1993.

COELHO, Fábio Ulhoa. Comentários à nova lei de falências e de recuperação de empresas. 4. ed. São Paulo: Saraiva, 2007.

COELHO, Fábio Ulhoa. Manual de Direito Comercial. 14. ed. São Paulo: Saraiva, 2003.

CUNHA, Paulo César Melo da. Regulação jurídica da Saúde Suplementar no Brasil. Rio de Janeiro: Lumen Juris, 2003.

DE LUCCA, Newton. Comentários aos arts. $1^{\circ}$ a $4^{\circ}$ da Lei 11.101. In: CORRÊA-LIMA, Osmar Brina; LIMA, Sérgio Mourão Corrêa (Coord.). Comentários à Nova Lei de Falência e Recuperação de Empresas: Lei no 11.101, de 09 de fevereiro de 2005. Rio de Janeiro: Forense, 2009. P. 29-72.

ESCOREL, Sarah. História das políticas de saúde no Brasil de 1964 a 1990: do golpe militar à reforma sanitária. In: GIOVANELLA, Lígia et al. (Coord.) Políticas e sistema de saúde no Brasil. 2. ed. Rio de Janeiro: Editora Fiocruz / Centro Brasileiro de Estudos da Saúde, 2012. P. 323-363.

ESPÍRITO SANTO. Tribunal de Justiça do Espírito Santo. Primeira Câmara Cível. Agravo de Instrumento $n^{0}$ 0010240-55.2015.8.08.0024. Vitória: Diário da Justiça, 15 jun. 2015.

FALCIANO, Rogério E. O regime concursal nas liquidações extrajudiciais e o direito de propriedade. In: SADDI, Jairo (Org.) Intervenção e liquidação extrajudicial no sistema financeiro nacional: 25 anos da Lei 6.024/74. São Paulo: Textonovo, 1999. P. 193-210.

FARIA, Werter R. Liquidação extrajudicial, intervenção e responsabilidade civil dos administradores das instituições financeiras. Porto Alegre: Fabris, 1985.

FERREIRA, Waldemar. Tratado de Direito Comercial. V. 5. São Paulo: Editora Saraiva, 1961.

FIGUEIREDO, Leonardo Vizeu. Curso de Direito de Saúde Suplementar: manual jurídico de planos e seguros de saúde. 2. ed. Rio de Janeiro: Forense, 2012.

GUASTINI, Riccardo. Estudios de teoría constitucional. 2. reimpressão. México: Fontamara, 2007. 
HENTZ, Luiz Antonio Soares; DINIZ, Gustavo Saad. Sociedades dependentes de autorização. São Paulo: IOB Thomson, 2004.

LIMA, Sérgio Mourão Corrêa; FONSECA, Humberto Lucena Pereira da. Comentários aos arts. 198 a 201 da Lei 11.101. In: CORRÊA-LIMA, Osmar Brina; LIMA, Sérgio Mourão Corrêa (Coord.). Comentários à Nova Lei de Falência e Recuperação de Empresas: Lei $n^{0} 11.101$, de 09 de fevereiro de 2005. Rio de Janeiro: Forense, 2009. P. 1.311-1.322.

MARQUES NETO, Floriano de Azevedo. Agências reguladoras: instrumentos de fortalecimento do Estado. Porto Alegre: Associação Brasileira das Agências de Regulação, 2003.

MELO, Alexandre José Paiva da Silva. Montesquieu: o diálogo necessário. In: ALMEIDA FILHO, Agassiz; BARROS, Vinícius Soares de Campos. Novo manual de ciência política. São Paulo: Malheiros, 2013.

MENDONÇA, Eliane Coelho. Insolvência Bancária: os Regimes Administrativos e o Procedimento Judicial de Falência. Revista da Procuradoria Geral do Banco Central, Brasília, v. 1, n. 1, p. 213243, dez. 2007.

MENDONÇA, José Xavier Carvalho de. Tratado de direito comercial brasileiro. V. 5. Tomo I. Atualizado por Ricardo Rodrigues Gama. Campinas: Russell Editores, 2005.

MINAS GERAIS. Tribunal de Justiça de Minas Gerais. Apelação Cível 1.0024.05.683945/002. Belo Horizonte: Diário da Justiça, 3 mar. 2010.

MIRANDA, Pontes de. Tratado de direito privado. Tomo 27. Atualizado por Vilson Rodrigues Alves. Campinas: Bookseller, 2003.

MÖLLERS, Christoph. The three branches: a comparative model of separation of powers. Oxford: Oxford University Press, 2013.

MONCADA, Luís S. Cabral de. Ensaio sobre a lei. Coimbra: Coimbra Editora, 2002.

OCKÉ-REIS, Carlos Octávio. SUS: o desafio de ser único. Rio de Janeiro: Fiocruz, 2012.

PITOMBO, Antônio Sérgio A. de Moraes (Coord.). Comentários à Lei de Recuperação de Empresas e Falência. 2. ed. São Paulo: Editora Revista dos Tribunais, 2007.

POSNER, Richard. A problemática da teoria moral e jurídica. São Paulo: WMF Martins Fontes, 2012.

REQUIÃO, Rubens. Curso de Direito Falimentar. 2. v. 14. ed. São Paulo: Saraiva, 1995.

RODRIGUES, Frederico Viana. Insolvência bancária: liquidação extrajudicial e falência. Belo Horizonte: Mandamentos, 2004.

SÃO PAULO (ESTADO). Tribunal de Justiça de São Paulo. Câmara Reservada à Falência e Recuperação. Apelação 0029514-15.2010.8.26.0562. São Paulo: Diário de Justiça, 15 mar. 2011. 
SÃO PAULO (ESTADO). Tribunal de Justiça de São Paulo. Primeira Câmara de Direito Privado. Agravo de Instrumento 2156313-96.2016.8.26.0000. São Paulo: Diário de Justiça, 2 fev. 2017.

SARRUBBO, Mariângela. A saúde na Constituição Federal e o contexto para recepção da Lei 9.656/98. In: MARQUES, Cláudia Lima; LOPES, José Reinaldo de Lima; PFEIFFER, Roberto Augusto Castellanos. Saúde e responsabilidade: seguros e planos de assistência privada à saúde. 1 . ed., 2. tir. São Paulo: Revista dos Tribunais, 1999. P. 13-22.

SIQUEIRA, Francisco José. Instituições financeiras: regimes especiais no direito brasileiro. Revista de Direito Bancário, do Mercado de Capitais e da Arbitragem, São Paulo, v. 4, n. 12, p. 44-71, abr./mar. 2001.

SUNSTEIN, Cass R. A Constitution of Many Minds: Why the Founding Document Doesn’t Mean What It Meant Before. Princeton: Princeton University Press, 2009.

WALD, Arnold. Da suspensão das ações e execuções em virtude da decretação da liquidação extrajudicial. Revista de direito mercantil, industrial, econômico e financeiro, São Paulo, nova série, v. 20, n. 41, p. 7-12, jan./mar. 1981.

Cássio Luís Casagrande

Professor Adjunto de Direito Constitucional na Universidade Federal Fluminense (Niterói/RJ). Docente Permanente no Programa de Pós-Graduação em Direito Constitucional PPGDC/UFF (Niterói/RJ). Doutor em Ciência Política pelo Instituto Universitário de Pesquisas do Rio de Janeiro (IUPERJ). Mestre em Relações Internacionais pela Pontifícia Universidade Católica do Rio de Janeiro (PUC-Rio). E-mail: cassio_casagrande@hotmail.com

Dalton Robert Tibúrcio Mestre em Direito Constitucional pela Universidade Federal Fluminense-UFF. Especialista em Advocacia Pública pela Universidade do Estado do Rio de Janeiro-UERJ. Procurador Federal em atuação junto à Agência Nacional de Saúde Suplementar. E-mail: daltonrobert2014@gmail.com 